\title{
Tensile properties and fracture locations of friction-stir-welded joints of 2017-T351 aluminum alloy
}

\author{
H.J. Liu ${ }^{\text {a,b, },}$, H. Fujii ${ }^{\text {a }}$, M. Maeda ${ }^{\text {a }}$, K. Nogi ${ }^{\text {a }}$ \\ a Joining and Welding Research Institute, Osaka University, Osaka 567-0047, Japan \\ ${ }^{\mathrm{b}}$ National Key Laboratory of Advanced Welding Production Technology, Harbin Institute of Technology, Harbin 150001, PR China
}

Received 30 October 2002; received in revised form 15 May 2003; accepted 5 June 2003

\begin{abstract}
Friction stir welding (FSW) is a new and promising welding process that can produce low-cost and high-quality joints of heat-treatable aluminum alloys because it does not need consumable filler materials and can eliminate some welding defects such as crack and porosity. In order to demonstrate the friction stir weldability of the 2017-T351 aluminum alloy and determine optimum welding parameters, the relations between welding parameters and tensile properties of the joints have been studied in this paper. The experimental results showed that the tensile properties and fracture locations of the joints are significantly affected by the welding process parameters. When the optimum revolutionary pitch is $0.07 \mathrm{~mm} / \mathrm{rev}$ corresponding to the rotation speed of $1500 \mathrm{rpm}$ and the welding speed of $100 \mathrm{~mm} / \mathrm{min}$, the maximum ultimate strength of the joints is equivalent to $82 \%$ that of the base material. Though the voids-free joints are fractured near or at the interface between the weld nugget and the thermo-mechanically affected zone (TMAZ) on the advancing side, the fracture occurs at the weld center when the void defects exist in the joints.
\end{abstract}

(C) 2003 Elsevier B.V. All rights reserved.

Keywords: Friction stir welding; Tensile properties; Welding parameter; Aluminum alloy; Fracture location

\section{Introduction}

Heat-treatable aluminum alloys are difficult to fusion weld because some welding defects such as crack and porosity are easily formed in the weld during the solidification of the welding pool [1]. Friction stir welding (FSW) is a solid phase welding process in which the metal to be welded is not melted during the welding, thus the crack and porosity often associated with fusion welding processes are eliminated [1,2]. Therefore, the FSW process can be used to weld heat-treatable aluminum alloys in order to obtain high-quality joints [1-4]. However, many studies on the microstructural characteristics and mechanical properties of the friction-stir-welded joints have indicated that FSW gives rise to softening in the joints of the heat-treatable aluminum alloys such as 2014-T651 [5], 2024-T3 [6,7], 2024-T351 [8,9], 2024-T6 [10,11], 2195-T8 [12,13], 6061-T5 [14,15], 6061-T6 [8,16-18], 6063-T5 [19-21], 6082-T5 [22], 7075-T651 [23] and 7475-T76 [7] because of the dissolution or growth of strengthening pre-

\footnotetext{
* Corresponding author. Tel.: +81-6-6879-8663.

E-mail addresses: lhj@jwri.osaka-u.ac.jp, liuhj@hope.hit.edu.cn (H.J. Liu).
}

cipitates during the welding thermal cycle, thus resulting in the degradation of the mechanical properties of the joints. Hence, it is important to study the effects of welding process parameters on the mechanical properties of the joints and determine the optimum welding parameters so as to obtain high-quality friction-stir-welded joints.

In the 2xxx-series heat-treatable aluminum alloys, 2014-T651, 2024-T3, 2024-T351 and 2024-T6 were friction stir welded in order to examine the tensile properties $[5-8,11]$ or fracture locations $[5,7,8]$ of the joints. The 2017-T351 aluminum alloy is one of the 2xxx-series heat-treatable aluminum alloys and it has not been friction stir welded up to now. This paper aims to demonstrate its friction stir weldability and the emphasis is placed on the relations of the tensile properties and fracture locations of the joints to the welding parameters in order to determine the optimum FSW parameters and find out the weakest locations of the joints.

\section{Experimental procedure}

The base material used in this study was a 2017-T351 aluminum alloy plate of $5 \mathrm{~mm}$ thick, whose chemical compositions and mechanical properties are listed in Table 1. The 
Table 1

Chemical compositions and mechanical properties of 2017-T351 aluminum alloy

\begin{tabular}{|c|c|c|c|c|c|c|c|c|c|c|c|}
\hline \multicolumn{9}{|c|}{ Chemical compositions (wt.\%) } & \multicolumn{3}{|l|}{ Mechanical properties } \\
\hline $\mathrm{Al}$ & $\mathrm{Si}$ & $\mathrm{Fe}$ & $\mathrm{Cu}$ & $\mathrm{Mg}$ & $\mathrm{Mn}$ & $\mathrm{Ti}$ & $\mathrm{Zn}$ & $\mathrm{Cr}$ & Tensile strength (MPa) & Proof strength, $0.2 \%(\mathrm{MPa})$ & Elongation $(\%)$ \\
\hline Balance & 0.52 & 0.29 & 4.29 & 0.60 & 0.58 & 0.02 & 0.08 & 0.02 & 428.1 & 319.2 & 23.8 \\
\hline
\end{tabular}

Table 2

Tool size and welding process parameters used in the experiments

\begin{tabular}{|c|c|c|c|c|c|c|}
\hline \multicolumn{4}{|l|}{ Tool size $(\mathrm{mm})$} & \multicolumn{3}{|l|}{ Welding parameters } \\
\hline Shoulder diameter & Pin diameter & Pin length & Tool tilt $\left({ }^{\circ}\right)$ & Rotation speed (rpm) & Welding speed $(\mathrm{mm} / \mathrm{min})$ & Revolutionary pitch (mm/rev) \\
\hline 15 & 6 & 4.7 & 3 & 1500 & $25-600$ & $0.02-0.40$ \\
\hline
\end{tabular}

plate was cut and machined into rectangular welding samples of $300 \mathrm{~mm}$ long by $80 \mathrm{~mm}$ wide, and the samples were longitudinally butt-welded using an FSW machine. The designated welding tool size and welding parameters are listed in Table 2.

After welding, the joints were cross-sectioned perpendicular to the welding direction for metallographic analyses and tensile tests using an electrical-discharge cutting machine. The cross-sections of the metallographic specimens were polished with alumina suspension, etched with Keller's reagent $(150 \mathrm{ml}$ water, $3 \mathrm{ml}$ nitric acid, $6 \mathrm{ml}$ hydrochloric acid and $6 \mathrm{ml}$ hydrofluoric acid) at $0{ }^{\circ} \mathrm{C}$ for about $10 \mathrm{~s}$, and observed by optical microscopy.

The configuration and size of the transverse tensile specimens were prepared with reference to JIS Z2201, and the marked length and width of each specimen were 50 and $12.5 \mathrm{~mm}$, respectively. Prior to the tensile tests, the Vickers hardness profiles across the weld nugget, thermo-mechanically affected zone (TMAZ), heat affected zone (HAZ) and partial base material were measured under the load of $0.98 \mathrm{~N}$ for $10 \mathrm{~s}$ along the centerlines of the cross-sections of the tensile specimens using an automatic micro-hardness tester, and the Vickers indents with a spacing of $0.5 \mathrm{~mm}$ were used to determine the fracture locations of the joints. The tensile tests were carried out at room temperature at a crosshead speed of $1 \mathrm{~mm} / \mathrm{min}$ using a computer-controlled testing machine and the tensile properties of each joint were evaluated using three tensile specimens cut from the same joint.

\section{Results and discussion}

\subsection{Experimental results}

\subsubsection{Tensile properties of joints}

Fig. 1 shows the tensile properties of the joints welded at different revolutionary pitches. It can be seen from the figure that the tensile properties of each joint are all lower than those of the base material (see Table 1). Especially, the elongation of the joint is far lower than that of the base material, and its maximum is merely $3.3 \%$.

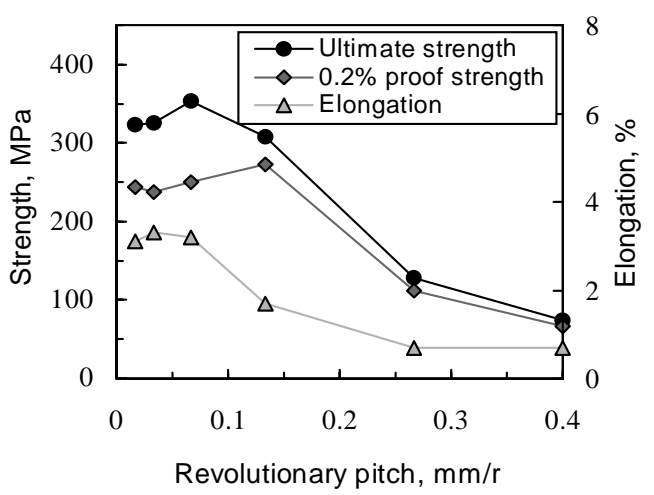

Fig. 1. Tensile properties of the joints.

When the revolutionary pitch is smaller than $0.13 \mathrm{~mm} / \mathrm{rev}$, the ultimate strength and $0.2 \%$ proof strength are at comparatively high levels and slightly increase with the revolutionary pitch. The maximum ultimate strength is obtained at the revolutionary pitch of $0.07 \mathrm{~mm} / \mathrm{rev}$. Its value is $354 \mathrm{MPa}$, equivalent to $82 \%$ that of the base material. When the revolutionary pitch is greater than $0.13 \mathrm{~mm} / \mathrm{rev}$, all the tensile properties, including ultimate strength, proof strength and elongation, dramatically decrease to considerably low levels.

These results indicate that a softening effect has occurred in the 2017-T351 aluminum alloy due to FSW just as it did in the other heat-treatable aluminum alloys. The softened levels or tensile properties of the joints are significantly affected by the welding parameters. The optimum welding parameters can be determined from the relation between the tensile properties and the welding parameters. When the rotation speed is designated as $1500 \mathrm{rpm}$, the welding speed of $100 \mathrm{~mm} / \mathrm{min}$ is optimum for the ultimate strength. In this case, the ultimate strength of the joint is equivalent to $82 \%$ that of the base material.

\subsubsection{Fracture locations of joints}

The fracture location of any joint is a direct reflection of the weakest part of the joint. Studying the fracture location of the joint is quite important to understand and improve the mechanical properties of the joint. Fig. 2 shows the strain 


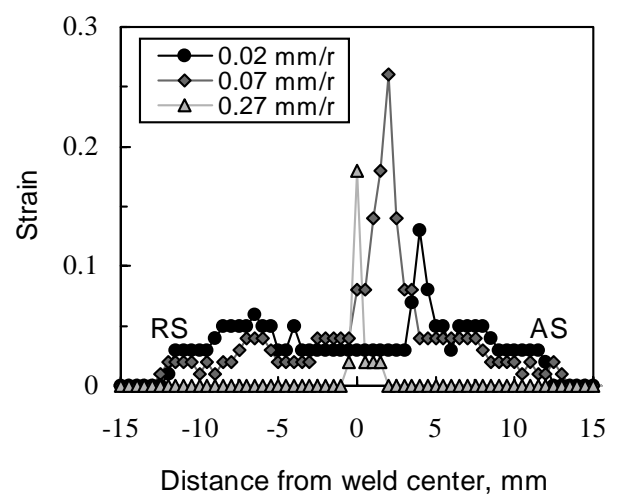

Fig. 2. Strain distributions in the typical joints.

distributions of the joints welded at the different revolutionary pitches. In this figure, the location at which the maximum strain of each joint occurs is the fracture location of the joint. In addition, the retreating side and advancing side of each joint are denoted by RS and AS, respectively.

It is observed from Fig. 2 that the strain distributions of the joints are located in a comparatively narrow region and the strain values are considerably low. Especially, the fracture locations of the joints are not distant from the weld center and change with the revolutionary pitches. When the revolutionary pitch is much smaller e.g. $0.02 \mathrm{~mm} / \mathrm{rev}$, the fracture location of the joint is only $4.1 \mathrm{~mm}$ from the weld center. When the revolutionary pitch increases to $0.07 \mathrm{~mm} / \mathrm{rev}$, the fracture location of the corresponding joint changes to $1.9 \mathrm{~mm}$ away. When the revolutionary pitch is equal to or greater than $0.27 \mathrm{~mm} / \mathrm{rev}$, the joints are all fractured at the weld center. That is to say, as the revolutionary pitch increases, the fracture location of the joint gradually approaches the weld center.

These results indicate that the joints are fractured under the conditions of local and heterogeneous deformation, and the fracture locations of the joints are significantly affected by the welding parameters. Moreover, it should be noted that all the joints are fractured on the advancing side or at the weld center, but not on the retreating side of the joints. This implies that the tensile properties of the joints are not the same on the two sides of the weld center, and the tensile

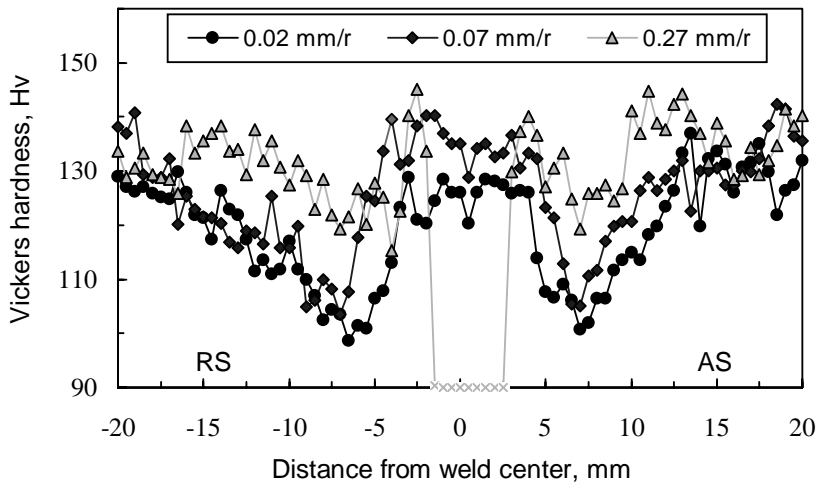

Fig. 4. Microhardness distributions of the typical joints welded at the different revolutionary pitches.

properties on the advancing side are weaker than those on the retreating side.

\subsection{Discussion}

A softened region has been formed in the joints of 2017-T351 aluminum alloy due to the effect of friction heat as occurred in the joints of other heat-treatable aluminum alloys $[7,21-23]$. The tensile properties and fracture locations of the joints are, to a large extent, dependent on the welding defects and hardness distributions of the joints, and which, in turn, on the welding parameters $[6,11,14]$. Figs. 3 and 4 show, respectively, the typical cross-sections and microhardness distributions of the joints welded at the different revolutionary pitches. When the revolutionary pitch is smaller than $0.13 \mathrm{~mm} / \mathrm{rev}$, FSW produces defect-free joints (see Fig. 3(a) and (b)). When the revolutionary pitch is greater than $0.13 \mathrm{~mm} / \mathrm{rev}$, some void defects are formed in the joints because of the lack of heat input to the joints (see Fig. 3(c)). When such void defects exist in the joints, the tensile properties and fracture locations of the joints are significantly affected by the defects. In Fig. 4, the hardness values at the void locations do not exist and are expressed by " $x$ ". These voids generally occur in the middle of the weld, thus seriously degrading the tensile properties of the joints and causing the joints to fracture at the weld center.

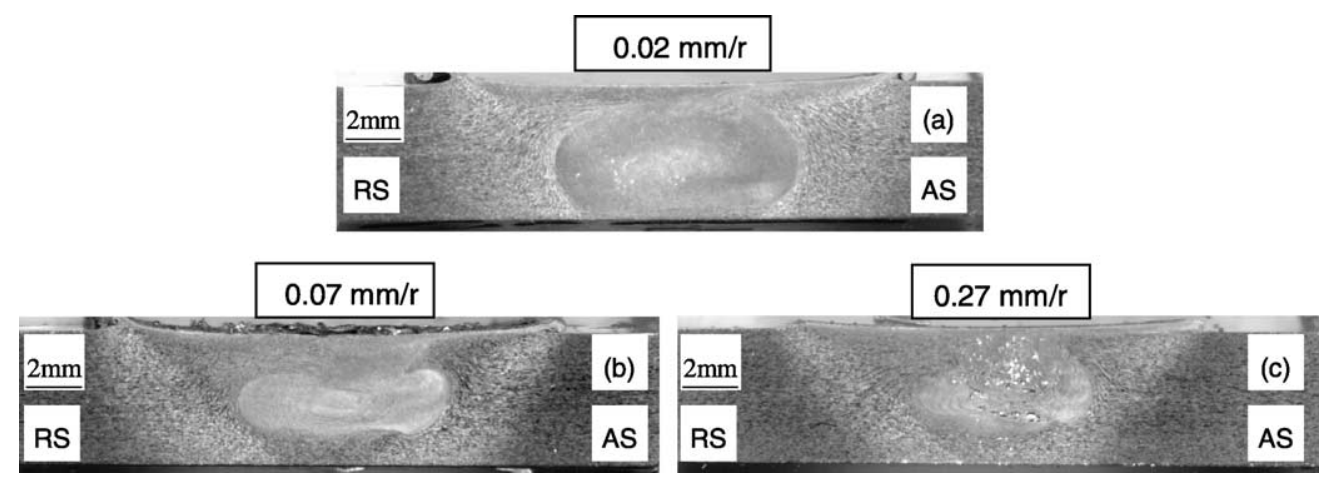

Fig. 3. Cross-sections of the typical joints welded at the different revolutionary pitches: (a) $0.02 \mathrm{~mm} / \mathrm{rev}$; (b) $0.07 \mathrm{~mm} / \mathrm{rev}$; and (c) $0.27 \mathrm{~mm} / \mathrm{rev}$. 
On the other hand, when a joint is free of defects, the tensile properties of the joint are only dependent on the microhardness distributions of the joint $[8,21,24]$. It can be seen from Figs. 3 and 4 that a hardness degradation region (i.e. softened region), composed of a weld (including a weld nugget and two TMAZs) and two HAZs, has occurred in the joints, thus the tensile properties of the joints are lower than those of the base material. Comparing Fig. 2 with Fig. 3(a) and (b), it is found that the fracture locations of the joints are at or near the interface between the weld nugget and the TMAZ on the advancing side. Moreover, the hardness value at the fracture location of the joint increases as the revolutionary pitch increases, consequently the tensile strength of the joint, including the ultimate strength and proof strength, increases with the revolutionary pitch.

In practice, the reason for the fracture at or near the interface between the weld nugget and the TMAZ is the remarkable difference in the internal structure between the weld nugget and the TMAZ. The weld nugget is composed of fine-equiaxed recrystallized grains, while the TMAZ is composed of coarse-bent recovered grains $[8,19]$. Therefore, the interface between the weld nugget and the TMAZ is clearly visible and becomes a weaker region or location in the joint, and the joint is fractured at this interface during the tensile testing. As the revolutionary pitch increases, the heat input to the joint decreases, and thus the weld nugget size becomes small and the distance of the weld center to the interface decreases. Accordingly, the fracture location of the joint approaches the weld center. When the revolutionary pitch is greater than a certain critical value, some void defects are formed in the middle of the weld, consequently the joint is fractured at the weld center.

In addition, it is known that the friction-stir-welded joint is a heterogeneous composite and its different component parts, including their interfaces, possess different mechanical properties $[8,24]$. When a tensile load is applied to the joint, the stress and strain concentration takes place in the lower-strength part or region of the joint, and consequently, the joint is fractured in this region [8]. As mentioned above, when the joints of 2017-T351 aluminum alloy are free of defects, the joints are fractured on the advancing side instead of the retreating side. This result is sufficient to indicate that the tensile strength on the advancing side is lower than that on the retreating side. In contrast, the joints of 6061-T6 aluminum alloy are fractured on the retreating side instead of the advancing side [25], showing that the different types of aluminum alloys demonstrate different fracture characteristics. These facts are important to deeply comprehend the FSW characterizations of different base materials.

\section{Conclusions}

A softened region, composed of a weld and two HAZs, has clearly occurred in the friction-stir-welded joints of the
2017-T351 aluminum alloy, thus the tensile properties of the joints are lower than those of the base material. The welding parameters have significant effects on the tensile properties and fracture locations of the joints. When the revolutionary pitch is greater than a definite value (e.g. $0.13 \mathrm{~mm} / \mathrm{rev}$ ), some void defects exist in the joints, the tensile properties of the joints are considerably low, and the joints are fractured at the weld center. On the other hand, when the revolutionary pitch is smaller than the definite value, no defects are formed in the joints, the tensile properties of the joints are at comparatively high levels, and the joints are fractured near or at the interface between the weld nugget and the TMAZ on the advancing side. Under the condition of an optimum revolutionary pitch of $0.07 \mathrm{~mm} / \mathrm{rev}$, the ultimate strength of the joint is maximum, equivalent to $82 \%$ that of the base material.

\section{References}

[1] C.J. Dawes, W.M. Thomas, Friction stir process welds aluminum alloys, Weld. J. 75 (1996) 41-45.

[2] K.E. Knipstrom, B. Pekkari, Friction stir welding process goes commercial, Weld. J. 76 (1997) 55-57.

[3] M.R. Johnsen, Friction stir welding takes off at boeing, Weld. J. 78 (1999) 35-39.

[4] G. Campbell, T. Stotler, Friction stir welding of armor grade aluminum plate, Weld. J. 78 (1999) 45-47.

[5] M.G. Dawes, S.A. Karger, T.L. Dickerson, J. Przyoatek, Strength and fracture toughness of friction stir welds in aluminum alloys, in: Proceedings of the Second International Symposium on Friction Stir Welding, Paper No. S2-P1, Gothenburg, Sweden, TWI Ltd. and IVF, June 2000.

[6] G. Biallas, R. Braun, C.D. Donne, G. Staniek, W.A. Kaysser, Mechanical properties and corrosion behavior of friction stir welded 2024-T3, in: Proceedings of the First International Symposium on Friction Stir Welding, Paper No. S3-P3, CA, USA, June 1999, TWI Ltd.

[7] L. Magnusson, L. Kallman, Mechanical properties of friction stir welds in thin sheet of aluminum 2024, 6013 and 7475, in: Proceedings of the Second International Symposium on Friction Stir Welding, Paper No. S2-P3, Gothenburg, Sweden, June 2000, TWI Ltd. and IVF.

[8] A.V. Strombeck, J.F.D. Santos, F. Torster, P. Laureano, M. Kocak, Fracture toughness behaviour of FSW joints on aluminum alloys, in: Proceedings of the First International Symposium on Friction Stir Welding, Paper No. S9-P1, California, USA, June 1999, TWI Ltd.

[9] G. Bussu, P.E. Irving, Fatigue performance of friction stir welded 2024-T351 aluminum joints, in: Proceedings of the First International Symposium on Friction Stir Welding, Paper No. S3-P1, CA, USA, June 1999, TWI Ltd.

[10] S. Benavides, Y. Li, L.E. Murr, D. Brown, J.C. Mcclure, Lowtemperature friction stir welding of 2024 aluminum, Scripta Mater. 41 (1999) 809-815.

[11] T. Hashimoto, S. Jyogan, K. Nakada, Y.G. Kim, M. Ushio, FSW joints of high strength aluminum alloy, in: Proceedings of the First International Symposium on Friction Stir Welding, Paper No. S9-P3, CA, USA, June 1999, TWI Ltd.

[12] D.G. Kinchen, Z.X. Li, G.P. Adams, Mechanical properties of friction stir welds in Al-Li 2195-T8, in: Proceedings of the First International Symposium on Friction Stir Welding, Paper No. S9-P2, CA, USA, June 1999, TWI Ltd. 
[13] T.U. Seidel, A.P. Reynolps, Visualization of the material flow in AA2195 friction-stir welds using a marker insert technique, Metall. Mater. Trans. A 32 (2001) 2879-2884.

[14] H. Okamura, K. Aota, M. Sakamoto, M. Ezumi, K. Ikeuchi, Behavior of oxide during friction stir welding of aluminum alloy and its influence on mechanical properties, Q. J. Jpn. Weld. Soc. 19 (2001) $446-456$.

[15] M. Kumagai, S. Tanaka, Properties of aluminum wide panels by friction stir welding, in: Proceedings of the First International Symposium on Friction Stir Welding, Paper No. S3-P2, CA, USA, June 1999, TWI Ltd.

[16] G. Liu, L.E. Murr, C.S. Niou, J.C. Mcclure, F.R. Vega, Microstructural aspects of the friction-stir welding of 6061-T6 aluminum, Scripta Mater. 37 (1997) 355-361.

[17] L.E. Murr, G. Liu, J.C. Mcclure, A TEM study of precipitation and related microstructures in friction-stir welded 6061 aluminum, J. Mater. Sci. 33 (1998) 1243-1251.

[18] Y. Nagano, S. Jogan, T. Hashimoto, Mechanical properties of aluminum die casing jointed by FSW, in: Proceedings of the Third International Symposium on Friction Stir Welding, Paper No. Post-12, Kobe, Japan, September 2001, TWI Ltd.
[19] Y.S. Sato, H. Kokawa, M. Enomoto, S. Jogan, Microstructural evolution of 6063 aluminum during friction-stir welding, Metall. Mater. Trans. A 30 (1999) 2429-2437.

[20] Y.S. Sato, H. Kokawa, M. Enomoto, S. Jogan, T. Hashimoto, Precipitation sequence in friction stir weld of 6063 aluminum during aging, Metall. Mater. Trans. A 30 (1999) 3125-3130.

[21] Y.S. Sato, H. Kokawa, Distribution of tensile property and microstructure in friction stir weld of 6063 aluminum, Metall. Mater. Trans. A 32 (2001) 3023-3031.

[22] J. Hagstrom, R. Sandstrom, Mechanical properties of welded joints in thin walled aluminum extrusions, Sci. Technol. Weld. Join. 2 (1997) 199-208.

[23] M.W. Mahoney, C.G. Rhodes, J.G. Flintoff, R.A. Spurling, W.H. Bingel, Properties of friction stir welded 7075-T651 aluminum, Metall. Mater. Trans. A 29 (1998) 1955-1964.

[24] H.J. Liu, H. Fujii, M. Maeda, K. Nogi, Heterogeneity of mechanical properties of friction stir welded joints of 1050-H24 aluminum Alloy, J. Mater. Sci. Lett. 22 (2003) 441-444.

[25] H.J. Liu, H. Fujii, M. Maeda, K. Nogi, Tensile properties and fracture locations of friction-stir welded joints of 6061-T6 aluminum Alloy, J. Mater. Sci. Lett. 22 (2003). 